\section{Lifetime costs and effectiveness of ReSTOR compared with a monofocal IOL and Array-SA40 in the Netherlands}

NE De Vries ${ }^{1}$, C Laurendeau², A Lafuma², G Berdeaux ${ }^{3,4}$ and RMMA Nuijts ${ }^{1}$

\section{Abstract}

Purpose To estimate the lifetime cost consequences for society and the National Health Service (NHS) of bilateral monofocal (SI40NB) or multifocal (ReSTOR or ArraySA40) intraocular lense (IOL) implantation after cataract surgery.

Setting Public hospital in the Netherlands. Methods A Markov model simulated three cohorts of patients followed 69 until 100 years of age, or death. Spectacle independence rates for each IOL were adjusted to the results of a randomized clinical trial that compared monofocal and multifocal Array-SA40 IOL implants, together with a prospective cohort of patients implanted with ReSTOR. Adjustment was performed using the propensity score method in a multivariate analysis. Resource consumption was estimated from a dedicated Dutch survey. Dutch unit costs were applied to spectacles, cataract surgery, IOLs, visits to ophthalmologists, optometrists, transport, and spectacle cleaning materials. Cost discounted at $4 \%$ and undiscounted economic results were calculated.

Results Spectacle independence rates were $\mathbf{8 6 . 0 \%}$ for ReSTOR, $\mathbf{8 . 7 \%}$ for monofocal IOLs, and $8.5 \%$ for Array-SA40. Patients lived without needing spectacles for $\mathbf{1 2 . 9}$ years after ReSTOR, for 1.4 years after monofocal IOLs, and 1.3 years after Array-SA40. ReSTOR patients bought 6.4 fewer pairs of spectacles than monofocal patients. Lifetime discounted cost consequences for the society were ReSTOR €3969, monofocal IOLs $€ 4123$, and Array-SA40 $€ 5326$. Corresponding costs for the NHS were $€ 2415$, $€ 2555$, and $€ 2556$, respectively.

Conclusions ReSTOR IOLs provided higher levels of spectacle independence than monofocal SI40NB or multifocal Array-SA40 IOLs resulting in savings, compared to a monofocal, over the period modelled of $€ 315$ for society and $€ \mathbf{1 4 0}$ for the NHS. Eye (2010) 24, 663-672; doi:10.1038/eye.2009.151; published online 3 July 2009

Keywords: cataract surgery; spectacle freedom; cost minimization; multifocal intraocular lens

Introduction

Typical senile cataract progresses slowly and if untreated can cause vision loss. It is the leading cause of blindness in the world affecting an estimated 20.5 million (17.2\%) Americans over 40 years of age. ${ }^{1-3}$ However, most populations in the Western world have access to cataract surgery, for example, 6.1 million American citizens $(5.1 \%)$ have pseudophakia/aphakia. It is predicted that Americans with cataract will increase to 30.1 million by 2020 of which 9.5 million are expected to undergo pseudophakia/ aphakia. ${ }^{1}$ Cataract surgery is the most frequently performed surgical intervention in the Netherlands and the number of cataract surgeries has increased from 80000 procedures per year in 1998 to 160000 procedures per year in 2006. ${ }^{4}$

More than $80 \%$ of patients regain good bestcorrected visual acuity (VA $>8 / 10$ Snellen equivalent) after cataract surgery, depending on other ocular pathologies and follow-up duration. ${ }^{5-9}$ Multifocal intraocular lenses (IOLs), implanted during presbyopia or cataract surgery, were developed to free patients from spectacles, by applying the principle of simultaneous vision. ${ }^{10}$ Improvements in multifocal IOL technology led to better VA over
${ }^{1}$ Department of

Ophthalmology, University Hospital Maastricht, Maastricht, The Netherlands

${ }^{2}$ Cemka, Bourg-la-Reine, France

${ }^{3}$ Health Economic, Europe, Alcon France,

Rueil-Malmaison, France

${ }^{4}$ Conservatoire National des Arts et Métiers, Chaire Economie et gestion des services de santé, Paris,

France

Correspondence:

G Berdeaux,

Health Economics,

Alcon France,

4, Rue Henri Sainte-Claire Deville,

Bat B, Rueil-Malmaison, Hauts-de-Seine F-92563, France

Tel: + 331471048 60; Fax: + 33147102770

E-mail: gilles.berdeaux@ alconlabs.com

Received: 23 February 2009 Accepted in revised form: 18 May 2009 Published online: 3 July 2009

Presentation: ISPOR, Athens, November 2008 
a longer range of distances and a degree of spectacle independence. ${ }^{11}$ Early designs of multifocal IOLs were associated with reduced contrast sensitivity, and complaints of halos and glare. Today, in routine practice, multifocal IOLs enable functional near and distance vision and an acceptable level of patient satisfaction. ${ }^{12-24}$ Recently, a new apodized multifocal IOL (Acrysof ReSTOR) was marketed. It provides good functional near, intermediate, and distance vision such that $80 \%$ of patients never wear spectacles again.

According to Vitale et $a l^{25}$ more than 110 million Americans can achieve normal vision after refractive correction. However, spectacle prescriptions incur costs for both patients and health insurance providers. The direct annual US cost of simply correcting impaired distance vision was at least $\$ 3.8$ billion, of which $\$ 780$ million related to persons aged $>65$ years. To the best of our knowledge, no data have been published on the costs associated with wearing spectacles after cataract surgery, apart from a survey by Cuq et al, ${ }^{26}$ covering France, Germany, Italy, and Spain, which found costs varying from $€ 230$ (Spain) to $€ 579$ (France). Cost savings have been estimated for 'laser-assisted in situ keratomileusis', ${ }^{27}$ but so far no lifelong data have been published for multifocal IOLs.

The aim of the present economic analysis was to compare the lifetime costs and consequences of cataract surgery with implantation of a multifocal ReSTOR IOL, a multifocal Array-SA40 IOL, and a monofocal PhacoFlex-SI40 NB IOL.

\section{Materials and methods}

\section{Effectiveness sources}

Data from a clinical trial ${ }^{28}$ that compared a monofocal IOL (PhacoFlex-SI40 NB; AMO, Irvine, CA, USA) to a multifocal IOL (Array-SA40; AMO). This randomized controlled trial included cataract patients with no ocular comorbidity. Near VA and distance VA were measured preoperatively, 3 months after first-eye surgery, and 3 months after second-eye surgery. Spectacle dependence, vision-related functioning, and patient satisfaction were collected as well. Multifocal IOLs showed significantly better uncorrected near VA than monofocal IOLs. Patients with multifocal IOLs were more likely to 'never' or 'only now and then' wear spectacles for near and distance than patients with monofocal IOLs. Satisfaction related to preoperative expectations was similar in the monofocal and multifocal groups.

These data were contrasted with data from a patient cohort implanted with the ReSTOR SN60D3 (Alcon Laboratories, Fort Worth, TX, USA) in a trial with similar follow-up and data collection. All patients had bilateral senile cataract, corneal astigmatism $\leqslant 1.5 \mathrm{D}$, and were followed-up for at least 6 months. VA and rates of spectacle independence in the three IOL groups were compared indirectly, after adjusting for potential confounding variables. Adjustment was performed by (1) linear regression and (2) the propensity score..$^{29,30}$ Potential confounding variables were demographic characteristics, preoperative near and distance vision, post-surgical follow-up time, and a neuroticism score. Neuroticism was expressed by the Neuroticism scale of the Eysenck Personality Questionnaire-Revised Short Scale, ${ }^{31}$ and ranged from 0 ('not at all neurotic') to 12 ('highly neurotic'). In addition, patients self-rated their uncorrected VA according to one of five categories, that is, 'Excellent' /'Good' / 'Satisfactory' / 'Fair' /'Poor'.

\section{Resource and unit cost}

A separate, dedicated, survey was performed to estimate the costs and resources associated with spectacle use after cataract surgery. The survey was conducted at 10 Dutch ophthalmologic centres. The selection of centres followed local advice on representative spectacle prescriptions. Centres were not selected at random. Each site was required to include $10-12$ patients meeting the following criteria:

- Age $\geqslant 45$ years at the time of cataract surgery

- Patients with senile cataract surgery in both eyes

- Patients needing spectacles after cataract surgery

- Patients capable of reading and understanding Dutch, knowing the objectives of the enquiry, and agreeing to participate in the survey (oral consent)

Collected information concerned the type and cost of spectacles purchased, distances to ophthalmologists and optic centres, and resources consumed in purchasing and caring for spectacles. Information was also gathered on the number of visits to ophthalmologists and optic centres, spectacle replacement frequencies, spectacle maintenance frequencies (at visits), the mean distance to care providers, and time spent (travel and spectacle cleaning) on vision care.

Two economic perspectives were considered, society and National Health Service (NHS). Results were expressed in Euros (2007) and a 4\% discount rate was applied.

National tariffs and survey estimates were used to cost consumed resources. Cataract surgery costs were estimated from the national DRG list. ${ }^{32}$ For the societal perspective, spectacle costs were calculated from Dutch optic centre statistics, ${ }^{33}$ transportation costs from market prices, and costs for 'time spent' from average Dutch wages. 


\section{Markov model}

An existing Markov model (Figure 1) was used to estimate the lifetime cost consequences for Dutch society and the NHS after bilateral ReSTOR implants when compared to the monofocal IOL and Array-SA40 implants. ${ }^{27,34,35}$ TreeAge software version 4.0

(Williamstown, MA, USA) was used to simulate cohorts of patients. Each cohort with a specified IOL implanted bilaterally during cataract surgery at age 69 years was followed until death or age 100 years. This age is representative of patients having cataract surgery in the EU countries. After surgery patients were assigned to one of two possible health states, spectacles either 'not needed' or spectacles 'needed and purchased'. The adjusted frequency rate of 'not needed' spectacles was derived from a pooled analysis of patients in the Nijkamp clinical trial ${ }^{28}$ and the ReSTOR cohort. During all subsequent cycles, patients could enter one of three visual states ('spectacles not needed', 'spectacles needed and purchased', or 'spectacles needed and not purchased') or the terminal state (death). The duration of a cycle was 1 month and patients were eliminated at death or upon reaching 100 years. National mortality statistics were used for life expectancy. ${ }^{36}$

Sensitivity analyses were performed on the discount rates $(0,4 \%)$ and costs of spectacles and time horizon $(10,20$, and 30 years).

\section{Results}

\section{Effectiveness comparison of three IOLs}

Data from 220 patients pooled from the Nijkamp clinical trial $^{28}$ and a prospective ReSTOR cohort were analysed. Patients were distributed as $n=83(37.7 \%)$ in the ReSTOR group, $n=69(31.4 \%)$ in the monofocal group, and $n=68(30.9 \%)$ in the Array-SA40 group. Table 1 presents demographic characteristics of all three groups at baseline.

The overall mean age was $68.8( \pm 12.4)$ years, but patients with ReSTOR implants were younger (62.3 years) than those in the other groups, that is monofocal IOL patients (72.3 years) and Array-SA40 patients (73.0 years) $(P<0.001)$. There was no gender difference between patients in the three IOL groups of which $40.0 \%$ were men. Also, the neuroticism score was significantly lower $(P=0.004)$ in patients with ReSTOR implants (mean 2.5) as compared to patients with monofocal IOL implants (mean 3.8) or Array-SA40 (mean 4.1).

Before surgery, mean uncorrected distance VA (LogMAR units) for the best eye was $0.48( \pm 0.3)$ and mean corrected distance VA was $0.23( \pm 0.24)$. Astigmatism (defined as cylinder $\leqslant-1$ ) affected $48.6 \%$ of patients and was bilateral in $15.0 \%$. Patients who subsequently received multifocal IOLs had the worst uncorrected near VA. Distance vision without spectacles was self-rated as 'Poor' by more than $45 \%$ of patients, and near vision without spectacles was rated as 'Poor' by $40 \%$. Only $6.1 \%$ of patients did not use spectacles, whereas $66.7 \%$ were dependant on spectacles for both near and distance vision.

Six months after surgery (Table 2) distance and near VA improved for all patients. Post-operative uncorrected distance VA did not differ significantly between the three implant groups. By contrast, notable differences of uncorrected near VA were observed between the IOL groups. Patients implanted with ReSTOR had a mean uncorrected near VA of $<0$ LogMAR that was significantly $(P<0.001)$ better than the monofocal IOL and Array-SA40 (mean of 0.18 and 0.08 LogMAR respectively). Self-rated near vision without spectacles was better with ReSTOR than with the other IOLs, and was rated as 'Excellent' or 'Good' by $83.6 \%$ of patients implanted with ReSTOR, compared to $26.2 \%$ for patients with the monofocal IOL and $32.4 \%$ with Array-SA40. Moreover, $86.4 \%$ of patients did not wear spectacles after ReSTOR implants, in contrast to only $8.5 \%$ of patients with monofocal IOLs and $8.1 \%$ with Array-SA40. Patients who continued to wear spectacles after ReSTOR implants did so for either distance or near vision only, but not for both. Also, spectacle types differed significantly $(P<0.001)$ according to the type of IOL implanted, such that patients with ReSTOR never needed bifocal or varifocal spectacles.

Table 3 reports results after adjustment for confounding factors, which did not change the results dramatically. After adjustment, uncorrected near VA was -0.21 LogMAR better for patients with ReSTOR, compared to monofocal implants $(P<0.001)$. Also, patients with ReSTOR had a greater probability of freedom from spectacles than patients with monofocal IOLs $(R R=10.2)$. The difference persisted and increased after adjustment for the propensity score $(R R=11.1)$. A similar difference in favour of ReSTOR was observed with the Array-SA40 comparison.

\section{Cost of refraction in the Netherlands}

Resources consumed by spectacle dependence are presented in Table 4. Spectacles were replaced approximately every 3 years (40 months) and a refraction visit (optometrist in nearly $50 \%$ of cases) was required for each pair of spectacles purchased. The mean time dedicated to IOL surgery was $16 \mathrm{~h}$ ( 2 workdays) per patient and a mean of 1.56 relatives attended each patient.

According to Table 2, spectacle types depended on the IOL implanted, for example patients with ReSTOR IOLs mostly bought distance spectacles costing $€ 227$. 


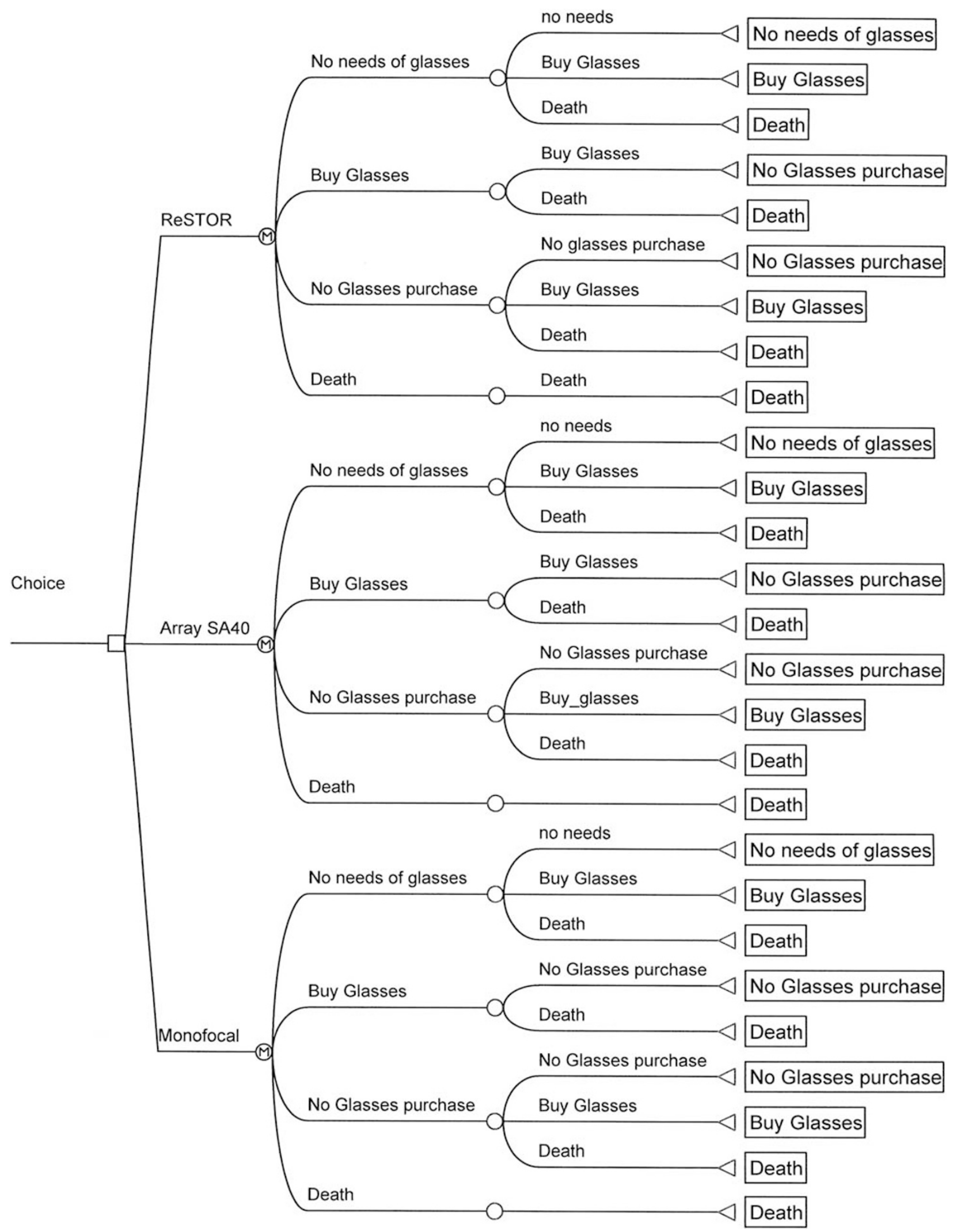

Figure 1 Scheme of the model. 
Table 1 Demographic characteristics at baseline

\begin{tabular}{|c|c|c|c|c|}
\hline Variable & Monofocal $(\mathrm{N}=69)$ & Array-SA40 $(\mathrm{N}=68)$ & $\operatorname{ReSTOR}(\mathrm{N}=83)$ & $\mathrm{P}$ \\
\hline Age (years) & $72.3(8.4)$ & $73.0(7.0)$ & $62.3(15.6)$ & $<0.001$ \\
\hline Male, \% (N) & $36.2(25)$ & $33.8(23)$ & $48.2(40)$ & 0.152 \\
\hline Neuroticism score & $3.8(3.3)$ & $4.1(3.3)$ & $2.5(2.6)$ & 0.004 \\
\hline Distance uncorrected visual acuity (best eye) & $0.49(0.28)$ & $0.46(0.25)$ & $0.49(0.41)$ & 0.753 \\
\hline Near uncorrected visual acuity (best eye) & $0.28(0.30)$ & $0.40(0.26)$ & $0.38(0.20)$ & 0.037 \\
\hline \multicolumn{5}{|l|}{ Type of astigmatism, \% (N) } \\
\hline Bilateral & $11.8(8)$ & $16.7(11)$ & $16.3(13)$ & 0.914 \\
\hline Unilateral & $33.8(23)$ & $34.8(23)$ & $32.5(26)$ & \\
\hline No astigmatism & $54.4(37)$ & $48.5(32)$ & $51.3(41)$ & \\
\hline
\end{tabular}

Table 2 Refraction at 6 months

\begin{tabular}{|c|c|c|c|c|}
\hline Refraction item & Monofocal & Array-SA40 & ReSTOR & $\mathrm{P}$ \\
\hline Distance uncorrected visual acuity (best eye) & $0.07(0.11)$ & $0.10(0.15)$ & $0.09(0.19)$ & 0.459 \\
\hline Near uncorrected visual acuity (best eye) & $0.18(0.21)$ & $0.08(0.14)$ & $-0.09(0.07)$ & $<0.001$ \\
\hline Patients free of spectacles, $\%(N)$ & $8.5(5)$ & $8.1(5)$ & $86.4(57)$ & $<0.001$ \\
\hline \multicolumn{5}{|l|}{ Population analysed: patient with spectacle dependency } \\
\hline Reading spectacles & $40.7 \%(22)$ & $61.4 \%(35)$ & $36.4 \%(4)$ & $<0.001$ \\
\hline Bifocal & $22.2 \%(12)$ & $21.1 \%(12)$ & $0 \%$ & \\
\hline Array-SA40 & $29.6 \%(16)$ & $10.5 \%(6)$ & $0 \%$ & \\
\hline Distance correction only & $3.7 \%(2)$ & $3.5 \%(2)$ & $54.5 \%(6)$ & \\
\hline Separate reading and distance spectacles & $3.7 \%(2)$ & $3.5 \%(2)$ & $9.1 \%(1)$ & \\
\hline
\end{tabular}

LogMar units were used for VA.

Table 3 Results of multivariate analysis

\begin{tabular}{lcccccrr}
\hline IOL comparison & & $\begin{array}{c}\text { Unadjusted } \\
\text { results }\end{array}$ & \multicolumn{2}{c}{$\begin{array}{c}\text { Adjusted results: } \\
\text { linear model }\end{array}$} & $\begin{array}{c}\text { Adjusted results: } \\
\text { propensity score }\end{array}$ \\
\hline $\begin{array}{l}\text { Results of linear regression model } \rightarrow Y=\text { Best uncorrected visual acuity in near vision } \\
\text { Multifocal IOL }\end{array}$ & Reference & Estimate & $\mathrm{P}$ & Estimate & $\mathrm{P}$ & Estimate & $\mathrm{P}$ \\
\hline ReSTOR & Monofocal & -0.268 & $<0.001$ & -0.213 & $<0.001$ & -0.229 & $<0.001$ \\
Array-SA40 & Monofocal & -0.104 & $<0.001$ & -0.102 & $<0.001$ & -0.110 & $<0.001$
\end{tabular}

Results of logistic regression model $\rightarrow Y=$ free of spectacles $(Y / N)$

\begin{tabular}{llrrrrrr}
\hline Multifocal IOL & Reference & $R R$ & $95 \% C I$ & $R R$ & $95 \% C I$ & $R R$ & $95 \%$ CI \\
\hline ReSTOR & Monofocal & 10.2 & $(3.2,32.3)$ & 10.5 & $(1.7,65.5)$ & 11.1 & $(1.1,42.6)$ \\
Array-SA40 & Monofocal & 1.0 & $(0.3,3.5)$ & 0.7 & $(0.1,3.1)$ & 1.0 & $(0.3,3.7)$
\end{tabular}

Contrast analyses

\begin{tabular}{lcccccc}
\hline IOL comparison & $R R$ & $\mathrm{P}$ & $R R$ & $\mathrm{P}$ & $R R$ & $\mathrm{P}$ \\
\hline Array-SA40 and ReSTOR vs monofocal & 10.3 & $<0.001$ & 10.4 & 0.002 & 11.4 & $<0.001$ \\
ReSTOR vs Array-SA40 & 10.7 & $<0.001$ & 11.8 & $<0.001$ & 11.3 & $<0.001$ \\
\hline
\end{tabular}

Spectacles with the other IOLs were mainly for reading (€108), but included more bifocal (€355.5) or varifocal lenses (€484), the most expensive. The average cost of spectacles after cataract surgery was $€ 193.5$ for ReSTOR, $€ 211.8$ for Array-SA40, and €287.5 for monofocal IOLs. The cost of implanting an IOL was $€ 137$, irrespective of 
the type. However, a patient co-payment of $€ 800$ was added to the cost of cataract surgery when a multifocal IOL was implanted, which was not reimbursed by the NHS. Spectacle cleaning costs were estimated at $€ 7$ and were not reimbursed by the NHS. Also, the Dutch NHS only partially reimbursed ophthalmologist visits; optometrist visits and spectacle costs were not reimbursed.

Table 4 Summary of Dutch refraction items entering cost analysis of spectacle dependence subsequent to cataract surgery

\begin{tabular}{lc}
\hline Refraction item & Quantity \\
\hline $\begin{array}{l}\text { Spectacles } \\
\text { Delay of renewal of spectacles (in months) or last }\end{array}$ & 40 \\
spectacles & \\
$\quad$ Number of broken spectacles (per month) & 0.19 \\
Time to purchase spectacles (minutes) & 31.22 \\
& \\
Visits for refraction & 51.1 \\
Ophthalmologist (\%) & 48.9 \\
Optometrist (\%) & 11.52 \\
Distance to ophthalmologist (km) & 11.52 \\
$\quad$ Distance to clinic (km) & 31.22 \\
Time lost when visiting ophthalmologist (min) & 480 \\
Time lost for operation (min) & \\
& \\
Visits to the optic centre & \\
$\quad$ Number of visits to the optic centre (per year) & 1.38 \\
$\quad$ For spectacles & 1.12 \\
$\quad$ For maintenance & 5.84 \\
\hline Distance to optic centre (km) &
\end{tabular}

Costs per kilometre of car travel were estimated at $€ 0.16$ and $€ 2.80$ for parking (Table 5). Taxi costs per kilometre were estimated at $€ 1.75$ and a $€ 2.80$ hire fee. Subway/bus costs were estimated at $€ 0.16$ per kilometre, depending on the distance travelled, type of ticket, etc). The average transportation cost per kilometre to visit ophthalmologists was $€ 3.22$ and to optic centres was $€ 1.71$.

\section{Comparative cost analysis}

The average life expectancy of our population aged 69 was 14.9 years. Patients implanted with ReSTOR gained an average of 11.5 years freedom from spectacles (Table 6). Compared to patients with monofocal IOLs or Array-SA40, patients with ReSTOR saved average lifetime costs of 3.7-6.4 spectacle pairs, 7.4-12.6 cleaning packs, 3.6-6.3 optical correction visits, $227.2-392.8 \mathrm{~km}$ of travel to optic centres and ophthalmologists, and 3.7-6.5 h spent on VA care.

From the societal perspective, at the end of our 30-year model (costs discounted at 4\%), patients implanted with ReSTOR spent less on spectacles and cleaning materials, visits for refraction, and transport, than patients with monofocal IOLs or Array-SA40 (Table 7). ReSTOR implants resulted in overall savings of $€ 315.4$ compared to monofocal IOLs. By contrast, Array-SA40 costs $€ 1203.9$ more than monofocal IOLs. Results with a $0 \%$ discount rate reinforced the previous differences.

Table 5 Unit costs $(€)$ according to country and type of resource consumed

\begin{tabular}{lccl}
\hline Cost item & Society & NHS & Data source \\
\hline Intraocular lens implant (1 unit) & & & \\
$\quad$ Cataract surgery & 933.0 & 1058.0 & Dutch costs \\
ReSTOR & 937 & 137 & Dutch costs \\
Array-SA40 & 937 & 137 & Dutch costs \\
Monofocal & 137 & 137 & Dutch costs \\
& & & Dutch Optic centre statistics pooled with \\
Spectacles after ReSTOR implant & 193.5 & 0 & results of analysis of database \\
After ReSTOR implant & 211.8 & 0 & \\
After Array- SA40 implant & 287.2 & 0 & Dutch costs \\
After Monofocal implant & 7.0 & 0 & Dutch costs \\
Cost of cleaning & 88.0 & 60.0 & Dutch costs \\
Visit for refraction & 40.0 & 0 & Dedicated survey \\
Ophthalmologist & & - & Dedicated survey \\
Optometrist & 3.22 & - & Dutch costs \\
Transportation mean cost for one visit & 1.71 & - &
\end{tabular}


Table 6 Average resources consumed as a function of time after ReSTOR, Array-SA40, and monofocal implants

\begin{tabular}{|c|c|c|c|c|c|c|c|c|c|}
\hline \multirow[t]{2}{*}{ Resource consumed } & \multicolumn{3}{|c|}{ ReSTOR } & \multicolumn{3}{|c|}{ Array-SA40 } & \multicolumn{3}{|c|}{ Monofocal } \\
\hline & 10 years & 20 years & 30 years & 10 years & 20 years & 30 years & 10 years & 20 years & 30 years \\
\hline Number of spectacles & 0.7 & 1.1 & 1.2 & 4.4 & 7.0 & 7.6 & 4.3 & 6.9 & 7.6 \\
\hline Number of units purchased to clean spectacles & 1.3 & 2.0 & 2.2 & 8.7 & 13.7 & 14.8 & 8.7 & 13.7 & 14.7 \\
\hline Visit to ophthalmologist to correct visual acuity & 0.6 & 1.0 & 1.1 & 4.2 & 6.7 & 7.4 & 4.2 & 6.7 & 7.3 \\
\hline Transportation ophthalmologist $(\mathrm{km})$ & 60.4 & 69.0 & 71.2 & 142.9 & 201.3 & 215.7 & 142.5 & 200.6 & 215.0 \\
\hline Transportation optic centre $(\mathrm{km})$ & 25.1 & 39.8 & 43.1 & 169.8 & 269.0 & 291.4 & 169.0 & 267.8 & 290.2 \\
\hline Time spent to care for visual acuity (h) & 41.6 & 42.0 & 42.1 & 45.3 & 48.0 & 48.6 & 45.3 & 47.9 & 48.6 \\
\hline \multicolumn{10}{|l|}{ Time spent (years) } \\
\hline With spectacles & & 2.0 & & & 13.6 & & & 13.5 & \\
\hline Without spectacles & & 12.9 & & & 1.3 & & & 1.4 & \\
\hline
\end{tabular}

Table 7 Cost consequences $(€)$ as a function of time after ReSTOR, Array-SA40, and monofocal implants (societal perspective)

\begin{tabular}{|c|c|c|c|c|c|c|c|c|c|}
\hline & \multicolumn{3}{|c|}{ ReSTOR } & \multicolumn{3}{|c|}{ Array-SA40 } & \multicolumn{3}{|c|}{ Monofocal } \\
\hline & 10 years & 20 years & 30 years & 10 years & 20 years & 30 years & 10 years & 20 years & 30 years \\
\hline \multicolumn{10}{|l|}{ Discount rate $=4 \%$} \\
\hline Cataract surgical procedure (including MIOL) & 3740.0 & 3740.0 & 3740.0 & 3740.0 & 3740.0 & 3740.0 & 2140.0 & 2140.0 & 2140.0 \\
\hline Spectacles & 104.0 & 147.1 & 154.6 & 769.0 & 1088.3 & 1143.5 & 1037.1 & 1467.9 & 1542.3 \\
\hline Cleaning materials & 1.5 & 2.1 & 2.1 & 10.0 & 13.9 & 14.5 & 9.9 & 13.8 & 14.4 \\
\hline Visit for refraction & 34.7 & 49.1 & 51.6 & 234.3 & 331.6 & 348.4 & 233.2 & 330.1 & 346.9 \\
\hline Transport & 17.5 & 20.3 & 20.8 & 57.3 & 76.4 & 79.6 & 57.1 & 76.1 & 79.3 \\
\hline Total 1: without time spent & 3897.7 & 3958.6 & 3969.1 & 4810.6 & 5250.2 & 5326.0 & 3477.3 & 4027.9 & 4122.9 \\
\hline Time costs & 1446.3 & 1454.1 & 1455.4 & 1556.5 & 1609.0 & 1617.8 & 1556.1 & 1608.3 & 1617.0 \\
\hline Total 2: with time spent & 5344.0 & 5412.7 & 5424.5 & 6367.1 & 6859.2 & 6943.8 & 5033.4 & 5636.2 & 5739.9 \\
\hline Difference with monofocal IOL & 310.6 & -223.5 & -315.4 & 1333.7 & 1223.0 & 1203.9 & Ref. & Ref. & Ref. \\
\hline \multicolumn{10}{|l|}{ Discount rate $=0 \%$} \\
\hline Cataract surgical procedure (including MIOL) & 3740.0 & 3740.0 & 3740.0 & 3740.0 & 3740.0 & 3740.0 & 2140.0 & 2140.0 & 2140.0 \\
\hline Spectacles & 120.4 & 192.9 & 210.8 & 890.3 & 1426.9 & 1559.4 & 1200.8 & 1924.5 & 2103.3 \\
\hline Cleaning materials & 1.8 & 2.8 & 3.0 & 12.0 & 18.8 & 20.3 & 11.9 & 18.8 & 20.2 \\
\hline Visit for refraction & 40.1 & 64.3 & 70.3 & 271.2 & 434.7 & 475.1 & 270.0 & 432.8 & 473.0 \\
\hline Transport & 18.7 & 23.5 & 24.6 & 65.4 & 97.9 & 105.5 & 65.2 & 97.5 & 105.1 \\
\hline Total 1: without time spent & 3921.0 & 4023.5 & 4048.7 & 4978.9 & 5718.3 & 5900.3 & 3687.9 & 4613.6 & 4841.6 \\
\hline Time spent & 1449.3 & 1462.4 & 1465.6 & 1576.9 & 1665.0 & 1686.1 & 1576.2 & 1664.0 & 1684.9 \\
\hline Total 2: with time spent & 5370.3 & 5485.9 & 5514.3 & 6555.8 & 7383.3 & 7586.4 & 5264.1 & 6277.6 & 6526.5 \\
\hline Difference with monofocal IOL & 106.2 & -791.7 & -1012.2 & 1291.7 & 1105.7 & 1059.9 & Ref. & Ref. & Ref. \\
\hline
\end{tabular}

Ref., reference case.

The NHS perspective yielded similar results (Table 8), except that differences between the IOLs were smaller because refraction costs were largely borne by patients.

\section{Conclusion}

The present economic analysis estimated cost consequences in the Netherlands following cataract surgery with implantation of a ReSTOR multifocal, an Array-SA40 multifocal, or a monofocal PhacoFlex-SI40
NB IOL, using a Markov model with cataract surgery at age 69 and patients followed until death, or age 100 years. The economic perspectives were those of society and the Dutch NHS. Monofocal IOLs represent today's care standard and are covered by the Dutch NHS. Multifocal IOLs have been introduced more recently and are only partially covered by the Dutch NHS. The current study uses an economic model to determine whether higher costs of a multifocal IOL are compensated by subsequent lower costs of spectacles due to higher levels of spectacle independence. ReSTOR IOLs provided 
Table 8 Cost consequences $(€)$ as a function of time after ReSTOR, Array-SA40, and monofocal implants (NHS perspective)

\begin{tabular}{|c|c|c|c|c|c|c|c|c|c|}
\hline & \multicolumn{3}{|c|}{ ReSTOR } & \multicolumn{3}{|c|}{ Array-SA40 } & \multicolumn{3}{|c|}{ Monofocal } \\
\hline & 10 years & 20 years & 30 years & 10 years & 20 years & 30 years & 10 years & 20 years & 30 years \\
\hline \multicolumn{10}{|l|}{ Discount rate $=4 \%$} \\
\hline Cataract surgical procedure (including ReSTOR) & 2390.0 & 2390.0 & 2390.0 & 2390.0 & 2390.0 & 2390.0 & 2390.0 & 2390.0 & 2390.0 \\
\hline Spectacles & 0.0 & 0.0 & 0.0 & 0.0 & 0.0 & 0.0 & 0.0 & 0.0 & 0.0 \\
\hline Visit to ophthalmologist for refraction & 16.5 & 23.3 & 24.5 & 111.3 & 157.5 & 165.5 & 110.8 & 156.9 & 164.8 \\
\hline Total & 2406.5 & 2413.3 & 2414.5 & 2501.3 & 2547.5 & 2555.5 & 2500.8 & 2546.9 & 2554.8 \\
\hline Difference with monofocal IOL & -94.3 & -133.6 & -140.3 & 0.5 & 0.6 & 0.7 & Ref & Ref & Ref \\
\hline \multicolumn{10}{|l|}{ Discount rate $=0 \%$} \\
\hline Cataract surgical procedure (including ReSTOR) & 2390.0 & 2390.0 & 2390.0 & 2390.0 & 2390.0 & 2390.0 & 2390.0 & 2390.0 & 2390.0 \\
\hline Spectacles & 0.0 & 0.0 & 0.0 & 0.0 & 0.0 & 0.0 & 0.0 & 0.0 & 0.0 \\
\hline Visit to ophthalmologist for refraction & 19.1 & 30.6 & 33.4 & 128.9 & 206.5 & 225.7 & 128.3 & 205.6 & 224.7 \\
\hline Total & 2409.1 & 2420.6 & 2423.4 & 2518.9 & 2596.5 & 2615.7 & 2518.3 & 2595.6 & 2614.7 \\
\hline Difference with monofocal IOL & -109.2 & -175.0 & -191.3 & 0.6 & 0.9 & 1.0 & Ref. & Ref. & Ref. \\
\hline
\end{tabular}

Ref, reference case.

higher levels of spectacle independence than did monofocal or Array-SA40 IOLs resulting in savings over the period modelled of $€ 315$ for society and $€ 140$ for the NHS.

Our study wholly concerned the Netherlands, using Dutch mortality rates and cataract prevalence data, and patient data derived from a previously published clinical trial. The consequent combination of national survey and clinical trial data provides a guarantee of good internal and external validity, as recommended by most health economics guidelines. ${ }^{37}$

Uncorrected distance VA was similar between the three IOLs; uncorrected near VA was better with multifocal IOLs than monofocal IOLs; and ReSTOR was the superior multifocal IOL, compared to Array-SA40. These results were complemented by the higher spectacle independence rate with ReSTOR implants. Although ReSTOR was not allocated randomly, the results adjusted by two methods were consistent with unadjusted findings. It should be noted that the spectacle types chosen contributed significantly to the economic outcome, as ReSTOR obviated the need for bifocal and varifocal lenses, that is, the most expensive alternatives.

With ReSTOR implants, fewer than $15 \%$ of patients required spectacles after cataract surgery, making this lens consistently more economically advantageous than monofocal or Array-SA40 IOLs, when calculated with a 30 -year time horizon and $4 \%$ discount rate.

At an incremental cost of $€ 800$ paid by patients for multifocal IOL implants, ReSTOR provided savings of $€ 315$ for society and $€ 140$ for the NHS. That the discount rate significantly modified our results is not surprising in view of the long follow-up period (up to 30 years) built into our model.
Two factors lay behind the economic benefit of ReSTOR, that is, time and spectacle independence. The difference between ReSTOR and Array-SA40 costs showed that when the spectacle independence rate difference is insufficient, multifocal implants will not produce savings compared to monofocal IOLs. The same point was made by Lafuma and Berdeaux. ${ }^{34,35}$

We adopted a very conservative approach when choosing our assumptions. The non-financial benefits of freedom from spectacles after cataract surgery were not considered by the present analysis, but Cuq et $a l^{26}$ found that approximately $50 \%$ of patients were willing to pay for this freedom. Previously, some ReSTOR patients reported broader vision (unrestricted by a spectacle frame), feelings of well-being, freedom, youthfulness, improved socialization, and so on. ${ }^{38}$

In our economic analysis, we have not taken into account the additional time required to prepare a patient for a multifocal implantation. This approach is certainly acceptable according to the NHS economic perspective because these resources are already included, at least theoretically, in the DRG value. However, according to a societal perspective, it would be worth estimating them and fix how much a DRG should be modified to account for the additional work. More broadly, time and motion analyses should be performed every time a new technology is available for cataract surgery to question the validity of the DRG value.

Also we have not accounted for IOL explantation because none of them were observed in this cohort. A $2-4 \%$ explantation incidence rate would lead to a $21-42 €$ additional cost.

Our analysis is subject to the following limitations: (1) no model can replace real longitudinal data, but the 
feasibility and economics of such a survey may be questioned; (2) we hypothesized that the prevalence rate of spectacle independence remains constant until death, whereas available information on the efficacy of ReSTOR and other multifocal IOLs does not cover many years, ${ }^{39-42}$ (3) the external validity of our spectacle cost survey could be challenged as ophthalmologists were not selected at random, but the cost structure was consistent with national statistics; ${ }^{33}$ (4) we fully costed savings from avoided refraction visits after ReSTOR, which may be disputed as refraction could be a marginal reason for ophthalmic visits. However, avoided visits were not a major component of ReSTOR savings.

Our model, applying to the Netherlands, showed that savings from ReSTOR implants mainly benefited society, that is, patients. The explanation is simply that multifocal IOL costs were excluded from the NHS budget, which paid for cataract surgery and monofocal IOLs only, but not the costs of subsequent refraction visits and spectacles; patients avoided costs relating to professional care and refraction only. It is worth noting that costs met by patients, including the supplementary multifocal IOL payment, exceeded those of the NHS. Hence, provided the procedure has been judged as effective and safe, our results support the argument that patients should be wholly free to control their own budget for refraction correction during cataract surgery, according to their financial circumstances, and without any economic control from the Dutch NHS. Any NHS that would deny them this right may be regarded as economically irrational and unfairly interventionist.

In conclusion, according to our data and model, ReSTOR was always a cost-saving alternative to monofocal IOLs implanted during cataract surgery, when viewed from both society and NHS perspectives. Various sensitivity analyses confirmed the robustness of our findings.

\section{Acknowledgements}

This analysis was supported by a grant from Alcon France SA, Rueil-Malmaison, France. The analysis was performed by Cemka Eval, Bourg-la-Reine, France. Dr Gilles Berdeaux is employed by Alcon France.

\section{References}

1 Congdon N, Vingerling JR, Klein BE, West S, Friedman DS, Kempen J et al. Prevalence of cataract and pseudophakia/ aphakia among adults in the United States. Arch Ophthalmol 2004; 122: 487-494.

2 Javitt JC, Wang F, West SK. Blindness due to cataract: epidemiology and prevention. Ann Rev Public Health 1996; 17: 159-177.
3 Agency for Health Care Policy and Research. Cataract in Adults: Management of Functional Impairment. AHCPR: Rockville, MD, 1993.

4 Netherlands Central Bureau of Statistics. http://statline. cbs.nl/StatWeb/table.asp?HDR $=\mathrm{T} \& \mathrm{LA}=\mathrm{nl} \& \mathrm{DM}=\mathrm{SLNL} \&$ $\mathrm{PA}=37296$ ned $\& \mathrm{D} 1=0-2,4-7,14-18,59-60,65 \& \mathrm{D} 2=0,5,10,15$, 20,25,30,35,40,45,(1-4)-1\&STB = G1).

5 Anmarkrund N, Bergaust B, Bulie T, Sand AB. Evaluation of a flexible one-piece open-loop anterior chamber lens Symflex 350B 3-4 years after implantation. Acta Ophthalmol 1993; 71: 796-800.

6 Pötzsch DK, Lösch-Pötzsch M. Four year follow-up of the MemoryLens. J Cataract Refract Surg 1996; 22: 1336-1341.

7 Schmack WH, Gerstmeyer K. Long-term results of the foldable CeeOn edge intraocular lens. J Cataract Refract Surg 2000; 26: 1172-1175.

8 Milazzo S, Turut P, Artin B, Charlin JF. Long-term follow-up of three-piece, looped, silicone intraocular lenses. J Cataract Refract Surg 1996; 22(Suppl 2): 1259-1262.

9 Linnola RJ, Holst A. Evaluation of a 3-piece silicone intraocular lens with poly(methyl methacrylate) haptics. J Cataract Refract Surg 1998; 24: 1509-1514.

10 Simpson MJ. The diffractive multifocal intraocular lens. Eur J Implant Refract Surg 1989; 1: 115-121.

11 Javitt JC, Steinert RF. Cataract extraction with multifocal intraocular lens implantation: a multinational clinical trial evaluating clinical, functional, and quality-of-life outcomes. Ophthalmology 2000; 107: 2040-2048.

12 Javitt JC, Wang F, Trentacost DJ, Rowe M, Tarantino N. Outcomes of cataract extraction with multifocal intraocular lens implantation: functional status and quality of life. Ophthalmology 1997; 104: 589-599.

13 Javitt JC, Jacobson G, Schiffman RM. Validity and reliability of the Cataract TyPE Spec: an instrument for measuring outcomes of cataract extraction. Am J Ophthalmol 2003; 136: 285-290.

14 Lindstrom RL. Food and Drug Administration study update. One-year results from 671 patients with the $3 \mathrm{M}$ multifocal intraocular lens. Ophthalmology 1993; 100: 91-97.

15 Rossetti L, Carraro F, Rovati M, Orzalesi N. Performance of diffractive multifocal intraocular lenses in extracapsular cataract surgery. J Cataract Refract Surg 1994; 20: 124-128.

16 Steinert RF, Post Jr CT, Brint SF, Fritch CD, Hall DL, Wilder $\mathrm{LW}$ et al. A prospective, randomized, double-masked comparison of a zonal-progressive multifocal intraocular lens and a monofocal intraocular lens. Ophthalmology 1992; 99: 853-861.

17 Steinert RF, Aker BL, Trentacost DJ, Smith PJ, Tarantino N. A prospective comparative study of the AMO ARRAY zonal-progressive multifocal silicone intraocular lens and a monofocal intraocular lens. Ophthalmology 1999; 106: 1243-1255.

18 Vaquero M, Encinas JL, Jimenez F. Visual function with monofocal vs multifocal IOLs. J Cataract Refract Surg 1996; 22: $1222-1225$.

19 Gimbel HV, Sanders DR, Raanan MG. Visual and refractive results of multifocal intraocular lenses. Ophthalmology 1991; 98: 881-888.

20 Blaylock JF, Si Z, Vickers C. Visual and refractive status at different focal distances after implantation of the ReSTOR multifocal intraocular lens. J Cataract Refract Surg 2006; 32: 1464-1473. 
21 Chiam PJ, Chan JH, Aggarwal RK, Kasabi S. ReSTOR intraocular lens implantation in cataract surgery: quality of vision. J Cataract Refract Surg 2006; 32: 1459-1463.

22 Souza CE, Gerente VM, Chalita MR, Soriano ES, Freitas LL, Belfort Jr R. Visual acuity, contrast sensitivity, reading speed, and wavefront analysis: pseudophakic eye with multifocal IOL (ReSTOR) vs fellow phakic eye in nonpresbyopic patients. J Refract Surg 2006; 22: 303-305.

23 Souza CE, Muccioli C, Soriano ES, Chalita MR, Oliveira F, Freitas LL et al. Visual performance of AcrySof ReSTOR apodized diffractive IOL: a prospective comparative trial Am J Ophthalmol 2006; 141: 827.

24 Kohnen T, Allen D, Boureau C, Dublineau P, Hartmann C, Mehdorn E et al. European multicenter study of the AcrySof ReSTOR apodized diffractive intraocular lens. Ophthalmology 2006; 113: 584.e1.

25 Vitale S, Cotch MF, Sperduto R, Ellwein L. Costs of refractive correction of distance vision impairment in the United States, 1999-2002. Ophthalmology 2006; 113: 2163.

26 Cuq C, Lafuma A, Jeanbat V, Berdeaux G. A European survey of patient satisfaction with spectacles after cataract surgery and the associated costs in four European countries (France, Germany, Spain and Italy). Ophthalmic Epidemiol 2008; 15: 234-241.

27 Berdeaux G, Alio J, Martinez J-M, Magaz S, Badia X. Socioeconomic aspects of laser in situ keratomileusis, spectacles, and contact lenses in mild to moderate myopia. J Cataract Refract Surg 2002; 28: 1914-1923.

28 Nijkamp MD, Dolders MG, de Brabander J, van den Borne B, Hendrikse F, Nuijts RM. Effectiveness of multifocal intraocular lenses to correct presbyopia after cataract surgery: a randomized controlled trial. Ophthalmology 2004; 111: $1832-1839$.

29 Yue LQ. Statistical and regulatory issues with the application of propensity score analysis to nonrandomized medical device clinical studies. J Biopharm Stat 2007; 17: 1-13; discussion 15-7, 19-21, 23-7 passim.

30 Zhang J, Yu KF. What's the relative risk? A method of correcting the odds ratio in cohort studies of common outcomes. JAMA 1998; 280: 1690-1691.

31 Sanderman R, Arrindell WA, Ranchor AV, Eysenck HJ, Eysenck SBG. Het meten van persoonlijkheidskenmerken met de Eysenck Personality Questionnaire (EPQ) —een handleiding.
Noordelijk Centrum voor Gezondheidsvraagstukken, Rijksuniversiteit Groningen: Groningen (NL), 1995; 1-34

32 Krabbe PFM, Adang EMM, Van der Wilt GJ. Lenzen bij cataractoperaties. Eindrapport. Nov 2006. Radboud University Medical Center http://www.cvz.nl/resources/ rpt-Radboud\%20lenzen-cataractoperaties_tcm28-22556.pdf.

33 CONSUMENTENONDERZOEK. PTIEKBRANCHE 2005. Dutch Optic Center Statistics. 2005 Hoofdbedrijfschap Detailhandel, Den Haag. The Netherlands.

34 Lafuma A, Berdeaux G. Modeling lifetime cost consequences of ReSTOR for presbyopia in four European countries. Eye 2009; 23: 1072-1080.

35 Lafuma A, Berdeaux G. Modeling lifetime cost consequences of ReSTOR in cataract surgery in four European countries. BMC Ophthalmol 2008; 8: 12.

36 Human Mortality Database. University of California, Berkeley (USA), and Max Planck Institute for Demographic Research (Germany). Available at www.mortality.org. or www.humanmortality.de. (data downloaded on 09/10/2007).

37 Hjelmgren J, Berggren F, Andersson F. Health economic guidelines - similarities, differences and some implications. Value Health 2001; 4: 225-250.

38 Berdeaux G, Viala M, Roborel de Climens A, Arnould B. Patient-reported benefit of ReSTOR(R) multi-focal intraocular lenses after cataract surgery: results of Principal Component Analysis on clinical trial data. Health Qual Life Outcomes 2008; 6: 10.

39 De Vries NE, Webers CA, Montes-Mico R, Tahzib NG, Cheng YY, de Brabander J et al. Long-term follow-up of a multifocal apodized diffractive intraocular lens after cataract surgery. J Cataract Refract Surg 2008; 34: 1476-1482.

40 Cillino S, Casuccio A, Di Pace F, Morreale R, Pillitteri F, Cillino $\mathrm{G}$ et al. One-year outcomes with new-generation multifocal intraocular lenses. Ophthalmology 2008; 115: 1508-1516.

41 Alfonso JF, Fernandez-Vega L, Baamonde MB, Montés-Micó R. Prospective visual evaluation of apodized diffractive intraocular lenses. J Cataract Refract Surg 2007; 33: 1235-1243.

42 Chang DF. Prospective functional and clinical comparison of bilateral ReZoom and ReSTOR intraocular lenses in patients 70 years or younger. J Cataract Refract Surg 2008; 34: 934-941. 